\title{
Polyploidy and invasion success: trait trade-offs in native and introduced cytotypes of two Asteraceae species
}

\author{
Aurélie Thébault • François Gillet • \\ Heinz Müller-Schärer • Alexandre Buttler
}

Received: 6 January 2010/ Accepted: 24 July 2010/Published online: 4 August 2010

(C) Springer Science+Business Media B.V. 2010

\begin{abstract}
Invasion success is favoured by the introduction of pre-adapted genotypes. In addition, novel pressures in the introduced range may lead to phenotypic changes related to fitness or competitive ability of introduced plants. Polyploidy appears to be over-represented in invasive plants, but differences between cytotypes in growth strategies including trade-offs among plant traits have received little
\end{abstract}

Electronic supplementary material The online version of this article (doi:10.1007/s11258-010-9824-8) contains supplementary material, which is available to authorized users.

A. Thébault $(\bowtie) \cdot$ F. Gillet $\cdot$ A. Buttler

Ecole Polytechnique Fédérale de Lausanne (EPFL),

Laboratory of Ecological Systems, Station 2,

1015 Lausanne, Switzerland

e-mail: aurelie.thebault@epfl.ch

A. Thébault · A. Buttler

Swiss Federal Research Institute WSL, Group Restoration

Ecology, co EPFL, 1015 Lausanne, Switzerland

F. Gillet · A. Buttler

Université de Franche-Comté, CNRS, UMR 6249

Chrono-Environnement, 16 route de Gray,

25030 Besançon cedex, France

H. Müller-Schärer

Unit of Ecology and Evolution, Department of Biology, University of Fribourg, Chemin du Musée 10,

1700 Fribourg, Switzerland attention so far in the context of biological invasions. We grew Centaurea stoebe L. and Senecio inaequidens D.C. in a greenhouse experiment to test for differences in fitness (shoot biomass, reproductive output) and competitive ability (vegetative size, specific leaf area, leaf dry matter content, root-shoot ratio) between diploid and polyploid cytotypes as well as between native and introduced plants. For both species, diploid and tetraploid genotypes occur in the native range, whereas only tetraploids are present in the introduced range. In the native range of both species, diploid and tetraploid genotypes had different growth strategies. Tetraploid genotypes of $C$. stoebe and $S$. inaequidens had, respectively, higher specific leaf area and stem height than diploid ones. Thus, for both species, native tetraploids appeared more competitive than native diploids, which could explain, at least partially, the invasion success of the pre-adapted tetraploid genotypes. The comparison of native and introduced tetraploid genotypes revealed differences in traits linked to competitive ability, which could be linked to novel selection in the new environment. In $S$. inaequidens, we found evidence for a competition-colonisation trade-off, whereas persistence of $C$. stoebe in the new range seemed to be linked to a competitiondefence trade-off.

Keywords Centaurea stoebe - Evolutionary processes - Invasiveness · Plant traits · Polyploidy · Senecio inaequidens 


\section{Introduction}

Invasive species represent a threat to natural and managed ecosystems (Pimentel et al. 2000; PrieurRichard et al. 2000). Understanding how they can invade ecosystems is a major challenge to ecologists (Richardson and Pysek 2006). Evolutionary processes such as hybridization or polyploidisation may cause intrinsic changes of the species which can lead to higher fitness (Hufbauer and Torchin 2007) or change in ecological breadth (Petit and Thompson 1999; Soltis and Soltis 2000; Weber and Schmid 1998). Especially in the last decade, evidence for adaptive evolutionary changes during the invasion process is increasing (Facon et al. 2006; Lee 2002; Prentis et al. 2008; Richards et al. 2006; Whitney and Gabler 2008). Given that these changes are detrimental in many cases, successful invaders probably result from selection on numerous hybrid combinations (Ellstrand and Schierenbeck 2000).

The process of invasion may be the result of a strong selection sequence leading to an assemblage of biological traits contributing to invasion success. Among others, one strategy to become a successful invader is to have a higher fitness (i.e. biomass production and reproductive output) than its native competitors in the new area (Colautti et al. 2006; Daehler 2003; Pyšek and Richardson 2007) and/or a higher competitive ability (Daehler 2003). The simultaneous study of fitness and competitive ability traits could give insights on traits related to invasiveness. Competitive ability can be encompassed by a small number of functional traits linked to light capture, production of biomass and nutrient use (Goldberg and Landa 1991; Keddy et al. 1998; Westoby 1998). Vegetative traits such as plant height or lateral spread of the canopy are known to be indicators of plant competition for light and space, respectively (Grime 1977). Specific leaf area (SLA), leaf dry matter content (LDMC) and root-shoot ratio (RSR) are traits related to growth rate and resource use and allocation (Navas and Moreau-Richard 2005; Reich et al. 1992). Classical studies in evolutionary ecology have often focused on variation in single traits. Only little attention has been paid to co-variation among characters, despite the fact that trade-offs have been recognised for their importance in explaining coexistence and local persistence (Silvertown 2004; Suding et al. 2003). SLA, LDMC and RSR are involved in the trade- off between production of biomass and conservation of nutrients (Reich et al. 1992) whereas capitulum production is linked to the competition-colonisation trade-off (Coomes and Grubb 2003). The study of trade-offs among traits and their directional co-variation might thus provide insights into pre-adapted lifehistory strategies for invasiveness (Chun et al. 2007; Kuster et al. 2008). According to the trade-off between production of biomass and resource use, competitive species should have higher SLA and lower LDMC compared to resistant ones, to ensure a fast cycling of nutrients and a rapid growth (Reich et al. 1999). The competition-colonisation trade-off states that competitive species should have larger seeds with short dispersal distance compared to colonisers (Coomes and Grubb 2003; Turnbull et al. 2004).

Intra-specific comparisons between native and introduced populations of an invasive species are of high importance to understand the invasion success. For a given species, this biogeographic comparison of ecological features can highlight critical traits and trait combinations that might enable plants to be more common in their introduced communities relative to their native ones (Hierro et al. 2005).

The aim of this experiment was to study the differences in plant fitness and competitive ability according to the different genotypes of invasive species. We used two invasive species, Centaurea stoebe L. and Senecio inaequidens D.C., which (1) both belong to the same family (Asteraceae), (2) occupy similar ecological niches in their native range (i.e. mainly dry meadows and habitats disturbed by human activities), and (3) tend to invade similar habitats in their introduced range (semi-natural and disturbed grasslands). Furthermore, these two species are assumed to have undergone polyploidisation by hybridization leading to the presence of diploid and tetraploid genotypes (Lafuma et al. 2003; Mrás et al. unpublished results). However, while both genotypes are predominantly present in discrete populations in their native range, the introduced range is exclusively dominated by tetraploid genotypes (Lafuma et al. 2003; Treier et al. 2009). According to recent studies, both diploid and tetraploid cytotypes may have been introduced in the new range, but only tetraploid ones managed to survive and spread, probably because of pre-adaptation to new environmental conditions (Bossdorf et al. 2008; Treier et al. 2009). If we define for convenience a geocytotype as a ploidy 
level in a given range (native or introduced range), both studied species have three geocytotypes: (1) native diploid, (2) native tetraploid, and (3) introduced tetraploid.

We performed a greenhouse experiment for 9 months. For both species, we compared fitness and competitive ability traits of the three geocytotypes. Comparison between native diploid and native tetraploid genotypes can indicate traits that might pre-adapt polyploids to become invasive in the introduced range, whereas comparison between native and introduced tetraploids may give insights into potential evolutionary changes following introduction in the new range. We hypothesised that (1) fitness of tetraploid genotypes is higher than fitness of diploid genotypes, and fitness of introduced tetraploids is higher than that of native tetraploids. Since several hypotheses regarding invasion success are linked to changes in traits related to competitive ability, we expected (2) both species' functional traits to differ between tetraploid geocytotypes so that plants in introduced populations should be taller, have lower LDMC, higher SLA and lower RSR than native ones. Furthermore, as evolutionary and ecological processes can affect trait co-variations and trade-offs, which could result in differences in growth strategy leading to invasive success, we hypothesised that for both species (3) trait trade-offs occurred between native diploid and native tetraploid genotypes, as well as between tetraploid genotypes, in a way that tetraploids are more competitive than diploids (higher SLA, lower LDMC, increased vegetative size) and introduced genotypes have higher colonisation ability than native genotypes (higher reproduction input).

\section{Materials and methods}

\section{Study species}

Centaurea stoebe L. (syn. C. maculosa Lam.) is an herbaceous biennial or short-lived perennial taprooted forb with a rosette of basal leaves and relatively thick flowering stems (Hook et al. 2004). Its native range spans from Western Asia to Western Europe, where diploid and tetraploid cytotypes appear in discrete populations (Broennimann et al. 2007). It was introduced in the Pacific Northwest of the US in the late 1800s (Watson and Renney 1974) and spread rapidly throughout US and Canada (Duncan 2001; Skinner et al. 2000). It causes substantial economic damage through its low nutritive value, which reduces forage quality (Campobasso et al. 1994). Tetraploid cytotypes are thought to have arisen from interspecific hybridization (Mráz et al. unpublished results). A niche shift has been observed between native and introduced populations (Broennimann et al. 2007), and especially between tetraploid genotypes. Introduced tetraploid genotypes mainly occur in areas with drier and more continental conditions than do tetraploids in Europe, but the niche of native diploids and tetraploids is largely overlapping (Treier et al. 2009).

Senecio inaequidens D.C. is an erect perennial dwarf shrub native to South Africa and Lesotho. In the native range, diploid and tetraploid cytotypes form discrete populations, with tetraploid ones being present in more mountainous area than diploid ones (Lafuma et al. 2003). It was accidentally introduced to Europe at the end of 1880s (Bornkamm 2002) where it is now widespread. It is also found in Australia and South America (see Ernst 1998 and Lafuma et al. 2003 for review). When growing in pastures, $S$. inaequidens is avoided by cattle, which leads to reduction of forage quality. Tetraploid cytotypes are thought to have arisen by interspecific hybridization and are thought to survive more stressful habitats than diploids (Lafuma et al. 2003).

Seed collection

Seeds of $C$. stoebe were collected during summer 2005 throughout its native range in Europe (Austria, Hungary, Switzerland and Ukraine) as well as in its introduced range in Montana and Oregon, US (Broennimann et al. 2007; Treier et al. 2009). Seeds of $S$. inaequidens (mostly provided by Dr. Daniel Prati, University of Leipzig-Halle and Sandrine Maurice, Institut des Sciences de l'Evolution Montpellier) were collected in Western Europe, South Africa and Lesotho (Lafuma et al. 2003).

Pot experiment

A 9-month pot experiment was set up in the greenhouse of the University of Lausanne, Switzerland. During February 2006, 180 seeds of each species were sown in germination trays filled with sieved garden 
soil from the University of Lausanne in which neither species grew previously. For each species, half of the seeds came from tetraploid introduced populations and half from native populations, either diploid or tetraploid. As ploidy level of seeds of $S$. inaequidens was known prior to the experiment, we used seeds from 45 diploid and 45 tetraploid parents from the native range, and 90 seeds from tetraploid parents from the introduced range. Since ploidy of $C$. stoebe was unknown at the beginning of the experiment and was analysed later, it came out that among native seeds, 70 seeds were from diploid parents and 20 from tetraploid parents. The 90 seeds from the introduced range were from tetraploid parents.

After 1 month, surviving seedlings (330 out of 360) were transplanted into $1 \mathrm{~L}$ pots. Each pot was filled with standard potting soil (mix of sand, peat and Swiss garden compost made of branches and leaves without any additional microorganisms, provided by Ricoter S. A., Aarberg, Switzerland) and contained one individual. Pots were randomly arranged on tables and watered every 2-4 days. For bio-security reasons and in order to prevent seed set, inflorescences of all plants were cut at weekly intervals during the experiment. We acknowledge that this cutting may have affected individual fitness, but since all the capitula were cut for all individuals, we consider that the cutting effect was the same for all individuals and geocytotypes. Nine months after sowing all living plants (212 individuals) were harvested and plant traits measured. Details on the origin of the seeds used for this study are given in Table S1 in the Electronic Supplementary Material.

\section{Measurements}

Shoot biomass and reproductive output (flowering ability, onset of flowering and capitulum production) were measured at the end of the experiment on all the 212 plants living. Flowering ability was recorded as a binary response of whether capitula were produced or not during the experiment. Number of days between sowing and the appearance of the first capitulum and the total number of capitula produced by flowering plants during the experiment were recorded to measure the onset of flowering and the capitulum production, respectively.
Due to time constraints, we randomly selected a subset of seven individuals of each geocytotype of both species for measurements of traits related to competitive ability (vegetative size, SLA, LDMC and RSR). On each selected individual, five leaves were taken randomly among the healthy fully developed ones for measurements of total leaf area, fresh and dry biomass (Cornelissen et al. 2003). Total leaf area was measured using a LI-3100C Leaf Area Meter (LiCOR, Lincoln, Nebraska, US). Leaves were dried at $60^{\circ} \mathrm{C}$ for $72 \mathrm{~h}$ and weighed for dry mass. Specific leaf area (SLA, leaf area per unit leaf dry mass in $\mathrm{m}^{2} \mathrm{~kg}^{-1}$ ) and leaf dry matter content (LDMC, leaf dry mass per unit of leaf fresh mass in $\mathrm{mg}^{-1}$ ) were calculated for each plant as the mean of measurements of its five selected leaves. These plants were then separated into shoots and roots, dried at $35^{\circ} \mathrm{C}$ for 7 days (to allow potential chemical analyses), and weighed together with the leaves collected for leaf trait measurements. Two distinct measures of vegetative size were done for the two species due to their distinct growth form: stem height for S. inaequidens and lateral extension of the canopy for C. stoebe (Grime 1977; Navas and Moreau-Richard 2005). Root-shoot ratio (RSR) was calculated as the ratio between root and shoot dry mass.

\section{Statistical analyses}

All the analyses were carried out with $\mathrm{R}$ 2.7.2 (R Development Core Team, 2008). Flowering ability binary data were analysed with a generalised linear model fitted with a binomial distribution and a logit link function (Venables and Ripley 1999) using the glm function of the stats library. Count data of onset of flowering and capitulum production of flowering plants were analysed with a generalised linear model fitted with a quasi-poisson distribution. Shoot biomass was analysed with a linear model which is more robust than analysis of variance for unbalanced designs (Pinheiro and Bates 2000). To reduce heteroscedasticity, shoot biomass was log-transformed. Since changes between geocytotypes can be species specific, analyses were performed separately for each species, after having tested the difference between species. Vegetative size, LDMC, SLA and RSR measured on the subset of $n=42$ individuals were analysed using analysis of variance (ANOVA using aov function) after having tested assumptions. To 
achieve the assumption of normality for analysis of variance and reduce heteroscedasticity, LDMC, SLA and vegetative size were log-transformed. Separate ANOVA were performed for each species to test for differences between geocytotypes within species. We used Tukey post-hoc tests to assess significant or marginally significant differences between levels of factors when needed. We considered marginally significant differences $(P<0.10)$ for the functional traits since the low number of replicates could show some trends that would need to be tested in a similar experiment with more replicates.

To study the multivariate response of traits, we performed a redundancy analysis (RDA) which constrained fitness and functional traits of the subset of individuals $(n=42)$ by species and geocytotype. Since vegetative size did not correspond to the same measure on the two species (plant height vs. lateral extension of the canopy), it was scaled at the species level before analysis to enable comparison between species. Permutation tests were used to assess the significance of these multivariate regression models.

\section{Results}

Comparison of traits among geocytotypes

Neither of the species differed significantly in shoot biomass among geocytotype (Table 1; Fig. 1a). The differences of reproductive outputs according to geocytotypes were species specific. There were no differences in flowering ability among geocytotypes of $S$. inaequidens, but introduced geocytotypes flowered significantly later than native diploid ones (Table 1; Fig. 1b). In addition, the number of capitula produced by introduced genotypes was higher than by native ones (Table 1; Fig. 1c). By contrast, the proportion of flowering individuals of native tetraploid geocytotypes of $C$. stoebe was significantly higher than that of the other geocytotypes $(70 \%$ of flowering individuals within native tetraploids vs., respectively, 37.2 and $29.2 \%$ within native diploid and introduced tetraploid geocytotypes, Table 1). The onset of flowering did not differ between geocytotypes (Table 1; Fig. 1b), but the number of capitula produced was higher for diploid genotypes than for tetraploid ones (Table 1; Fig. 1c).

Native diploid and tetraploid genotypes showed differences in various functional traits according to the species considered. Within native geocytotypes of C. stoebe, tetraploid cytotypes had a lower LDMC (Table 2; Fig. 2a) and a higher SLA (Table 2; Fig. 2b) than diploid cytotypes. These traits did not differ significantly between native diploid and native tetraploid genotypes of $S$. inaequidens, whereas tetraploid individuals were taller than diploid individuals (Table 2; Fig. 2d). Functional traits were not significantly different between introduced tetraploid and native tetraploid genotypes for either of the plant species studied.

Trait trade-offs among geocytotypes of both species

The measured functional traits clearly separated the two species in the redundancy analysis (Fig. 3) revealing two growth strategies (999 permutations, $P<0.001)$. The first axis represented the strategy of resource allocation. It separated $C$. stoebe with a high resource allocation to roots from $S$. inaequidens that invested into shoot biomass and flowering. Species

Table 1 Results of the analyses of differences in performance traits according to geocytotypes using linear model and generalised linear models

\begin{tabular}{|c|c|c|c|c|c|c|c|c|c|c|c|c|}
\hline & \multicolumn{3}{|c|}{ Shoot biomass $^{\mathrm{a}}$} & \multicolumn{3}{|c|}{ Flowering ability ${ }^{\mathrm{b}}$} & \multicolumn{3}{|c|}{ Capitulum production $^{\mathrm{b}}$} & \multicolumn{3}{|c|}{ Onset of flowering $^{b}$} \\
\hline & $d f$ & $F$ value & $P$ value & $d f$ & $F$ value & $P$ value & $d f$ & $F$ value & $P$ value & $d f$ & $F$ value & $P$ value \\
\hline C. stoebe & 2 & 0.865 & 0.424 & 2 & 147.53 & 0.047 & 2 & 14.733 & $<0.001$ & 2 & 1.792 & 0.1801 \\
\hline Residuals & 115 & & & 115 & & & 39 & & & 39 & & \\
\hline S. inaequidens & 2 & 0.007 & 0.993 & 2 & 14.83 & 0.104 & 2 & 3.099 & 0.049 & 2 & 8.959 & $<0.001$ \\
\hline Residuals & 91 & & & 91 & & & 89 & & & 89 & & \\
\hline
\end{tabular}

\footnotetext{
a Analysed with linear model

b Analysed with generalized linear model
} 
a

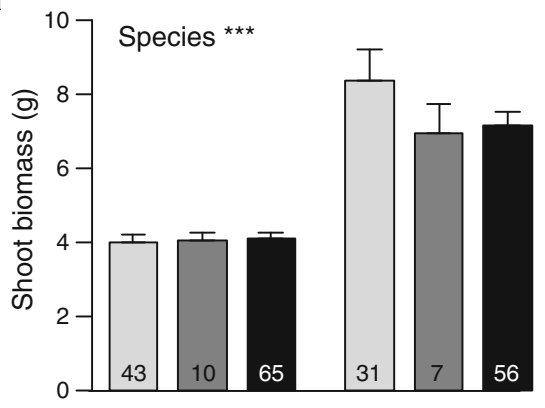

b

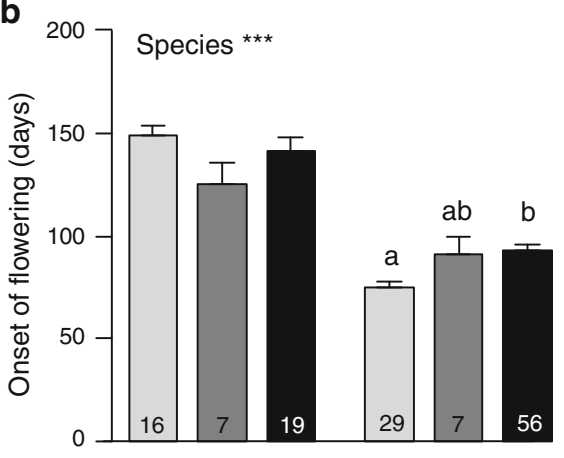

C

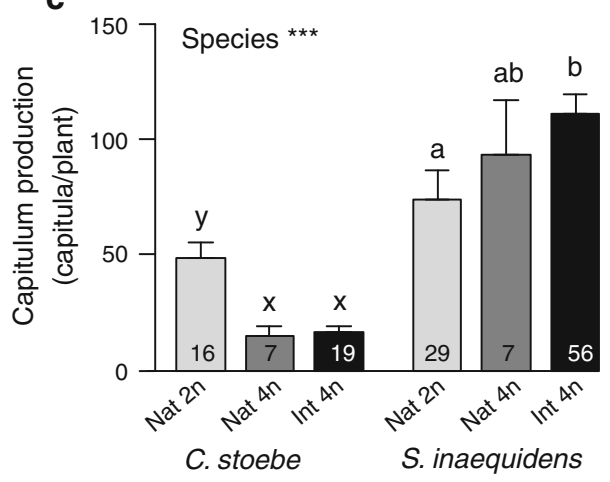

Fig. 1 Shoot biomass and reproductive traits (onset of flowering and capitulum production) of geocytotypes [native diploid Nat $2 n$ (light grey), native tetraploid Nat $4 n$ (grey) and introduced tetraploid Int $4 n$ (black)] of Centaurea stoebe (left side) and Senecio inaequidens (right side). Numbers of individuals considered for each geocytotype are given at the bottom of histograms. Bars indicate the standard error of the mean. Significant differences between species are indicated as $* P<0.05$, ** $P<0.01$, *** $P<0.001$. Significant differences between geocytotypes are indicated with different letters (according to Tukey post-hoc tests)

were significantly different regarding functional traits linked with competitive ability (Fig. 2) as C. stoebe had a higher RSR (Fig. 2c, $F_{1,40}=42.65$, $P<0.001)$, showing a higher allocation in roots than $S$. inaequidens.
The second axis indicated the nutrient acquisition/ conservation strategy of the plants. This axis was not significant, thus there was no clear differentiation of species and geocytotypes along this gradient. However, although geocytotypes of both species had mean SLA between 11 and $21 \mathrm{~m}^{2} \mathrm{~kg}^{-1}$ and mean LDMC ranging from 160 to $235 \mathrm{mg} \mathrm{g}^{-1}, C$. stoebe had a significantly higher LDMC (Fig. 2a, $F_{1,40}=7.72$, $P=0.008$ ) and lower SLA (Fig. $2 b, F_{1,40}=5.16$, $P=0.029)$ than $S$. inaequidens. Within each species there was a continuum from individuals with nutrient conservation strategy (high LDMC) to individuals with highly competitive strategy through resource investment in rapid growth (high SLA), with a tendency of introduced tetraploid geocytotypes having an "intermediate" strategy, as shown by the position of centroids on the RDA biplot. RDA constrained by species only (not shown) indicated that species explained $29.7 \%$ of the total variation of traits, which was significant $\left(F_{1,40}=13.01\right.$, $P<0.005)$, while RDA constrained by geocytoype (not shown) indicated that geocytotype explained only $2.5 \%$ of total trait variation, which was not significant $\left(F_{2,39}=0.88, P=0.53\right)$.

\section{Discussion}

Differences between the species

Both species were characterised by high values of SLA and low values of LDMC, which is typical for species with fast relative growth rate in relation to fast acquisition of resources (Cornelissen et al. 2003; Navas and Moreau-Richard 2005; Poorter and De Jong 1999; Weiher et al. 1999). Thus, both species could be defined as exploitative species (Diaz et al. 2004; Grime 1979; Wright et al. 2004). However, species had different sets of trait values, which gave them distinct growth strategies, as shown by the RDA biplot. Centaurea stoebe was characterised by a higher investment in leaf toughness (higher values of LDMC) and a higher resource-allocation to belowground parts (as shown by higher values of RSR) than $S$. inaequidens. This resource allocation to leaf tissues and belowground parts can be linked to resource conservation and resistance against physical hazards or herbivory (Cornelissen et al. 2003). Senecio inaequidens was characterised by a higher investment 
Table 2 Analysis of variance on functional traits related to competitive ability of the three geocytotypes for both species $(n=21$ for each species)

\begin{tabular}{|c|c|c|c|c|c|c|c|c|c|}
\hline & \multicolumn{3}{|c|}{ LDMC } & \multicolumn{2}{|l|}{ SLA } & \multicolumn{2}{|c|}{ Vegetative size } & \multicolumn{2}{|l|}{ RSR } \\
\hline & $d f$ & $F$ value & $P$ value & $F$ value & $P$ value & $F$ value & $P$ value & $F$ value & $P$ value \\
\hline C. stoebe & 2 & 2.891 & 0.082 & 4.735 & 0.022 & 0.147 & 0.864 & 0.973 & 0.397 \\
\hline Residuals & 18 & & & & & & & & \\
\hline S. inaequidens & 2 & 0.325 & 0.727 & 0.202 & 0.819 & 3.119 & 0.069 & 0.024 & 0.976 \\
\hline Residuals & 18 & & & & & & & & \\
\hline
\end{tabular}
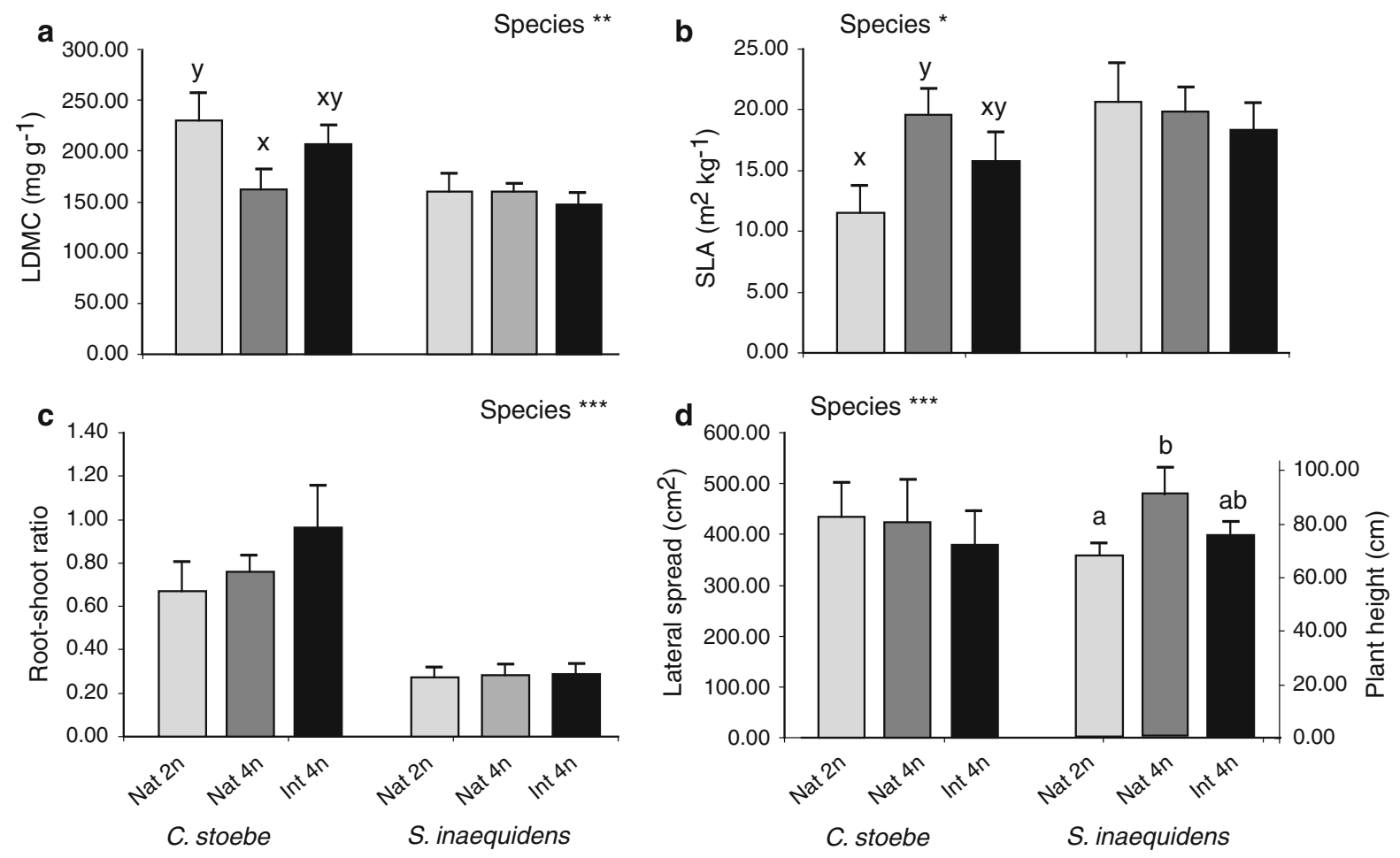

Fig. 2 Functional traits linked to competitive ability of geocytotypes [native diploid Nat $2 n$ (light grey), native tetraploid Nat $4 n$ (grey) and introduced tetraploid Int $4 n$ (black)] of Centaurea stoebe (left side) and Senecio inaequidens (right side). Vegetative size corresponds to lateral extension of the canopy $\left(\mathrm{cm}^{2}\right)$ for $C$. stoebe, and plant height

(cm) for S. inaequidens. Bars indicate the standard error of the mean. Significant differences between species are indicated as $* P<0.05$, ** $P<0.01$, *** $P<0.001$. Differences (up to $10 \%$ ) between geocytotypes of each species are indicated with different letters (according to Tukey post-hoc tests)

in shoot biomass and reproductive outputs, contributing to a higher competitive effect and leading to longer persistence in the environment (Goldberg and Landa 1991; Navas and Moreau-Richard 2005; Weiher et al. 1999) than C. maculosa.

Both species showed differences in reproductive output between geocytotypes, however, we found these differences to be species specific. While the

number of flower heads of $C$. stoebe was higher in diploid than in tetraploid genotypes, polyploid $S$. inaequidens invested more in flowering potential than diploid genotypes, as shown by the higher number of flower heads produced. By increasing capitulum production, introduced geocytotypes of $S$. inaequidens enhanced propagule pressure in the new area, which has often been considered as a major 
Fig. 3 Redundancy analysis $(R D A)$ on fitness and functional traits of Centaurea stoebe (black symbols) and Senecio inaequidens (white symbols). Grey diamonds represent centroids of species and geocytotypes. Axes 1 and 2 represent, respectively, $24.72 \%$ (999 permutations, $P=0.005$ ) and $3.23 \%(999$ permutations, $P=0.270$ ) of total trait variation $(n=42)$

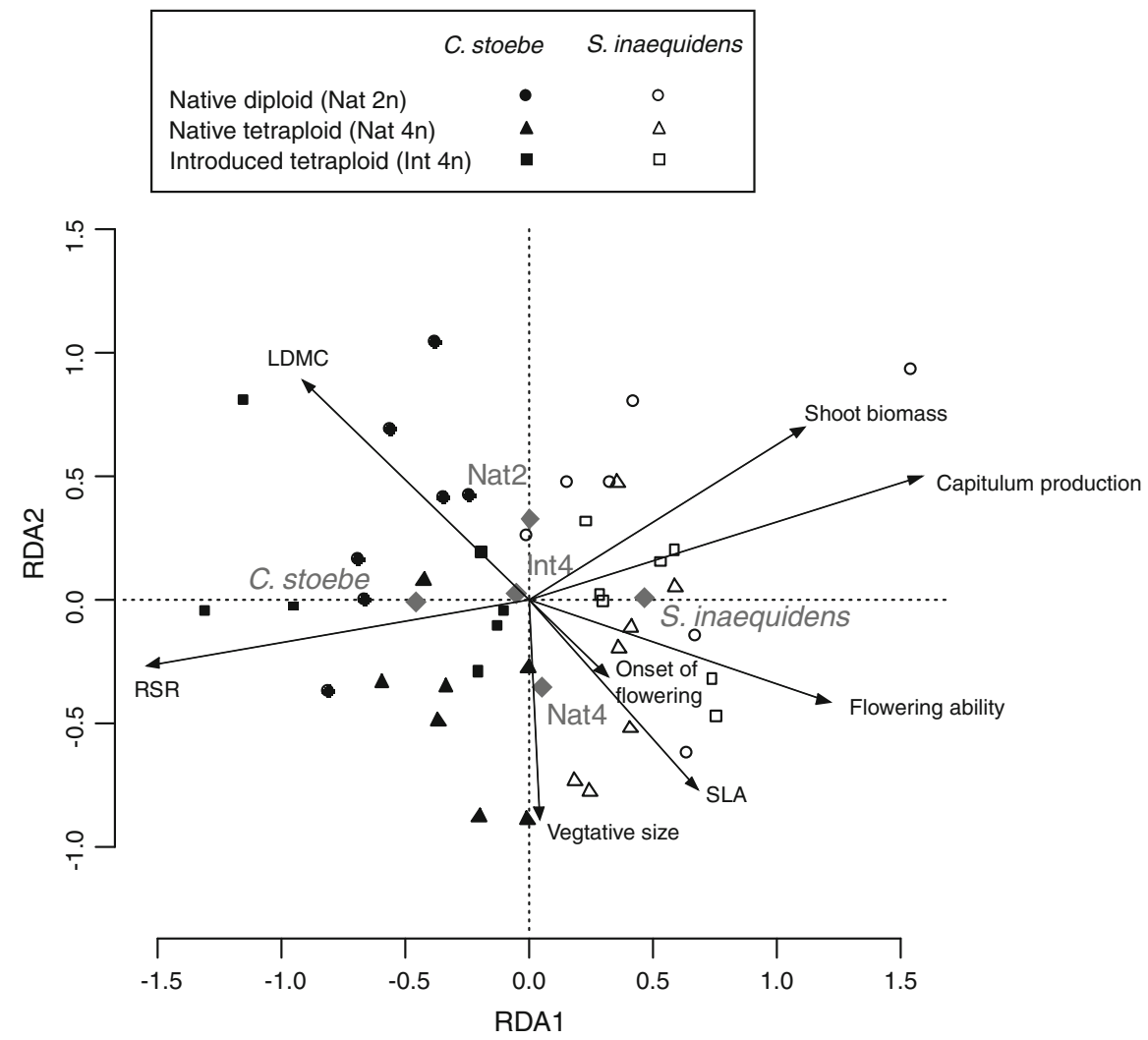

component of invasion success (Kolar and Lodge 2001; Lockwood et al. 2005; Von Holle 2005; Williamson 1996), because it enhances chances of establishment and subsequent potential for spreading. By contrast, tetraploid geocytotypes of C. stoebe showed a decrease in flowering potential. Previous results for this species also showed that tetraploid geocytotypes produced significantly less seeds per flowering plant than diploid geocytotypes, mainly due to a lower number of seeds per capitula (Henery et al. 2010). Lower reproductive effort in tetraploid genotypes could be the result of changes in allocation to defence or traits related to persistence (Henery et al. 2010).

Thus, even among invasive species of the same family living in ecologically similar habitats, life strategies can be markedly different. This explains the difficulties in finding key traits related to invasiveness at this taxonomic level (Muth and Pigliucci 2006) and stresses the need for selecting pertinent functional traits that can best reveal the mechanisms by which certain species become invasive in their introduced range.
Traits trade-offs during invasion process

Invasion of both species might be due to pre-adaptation of the cytotypes to the conditions in the new range, since traits related to competitive ability differed in the native range between diploid and tetraploid genotypes. In the native range of $S$. inaequidens, polyploidy was linked to higher stem height. Taller plants can quickly overgrow the surrounding vegetation and therefore better compete for light in the early growing season. Within the native range of $C$. stoebe, tetraploid geocytotypes invested more resources in photosynthetic tissues (higher SLA) and less in defence components (lower LDMC), allowing them faster growth and nutrient cycling. For both species, the higher competitiveness of tetraploid over diploid genotypes might explain the establishment success of the tetraploid genotypes when introduced in a new area as compared to the diploid considering that diploid genotypes have also been introduced (Henery et al. 2010; Lafuma et al. 2003; Treier et al. 2009).

Compared to tetraploid native geocytotypes, tetraploid introduced geocytotypes of both species showed 
more generalised strategies. Vegetative height in introduced $S$. inaequidens was lower suggesting that novel pressures in the introduced range may have led to selection for greater allocation to flowering and decreased investment in overtopping. The trade-off between flowering and growth could therefore explain why introduced genotypes were not taller than native ones. In C. stoebe, defence characteristics were more apparent in introduced genotypes (lower SLA, higher LDMC). The fast cycling strategy linked to high competitive ability could have been beneficial in the initial stages of invasion (Guesewell et al. 2006), but subsequent spread would have selected individuals more adapted to herbivory and perturbations, through unpalatable and resistant tissues. Besides effects of selection in the new range, these results could also simply be due to genetic drift. However, by using plants from various populations covering a large area of the distribution in both native and introduced ranges, we tried to minimise effects of genetic drift.

Thus, these results allow us to argue in favour of a two-phase invasion, as described by Dietz and Edwards (2006), where high competitive ability of native tetraploids would have permitted them to invade low stressed and rich habitats, and where subsequent evolutionary changes towards a less competitive and more stress tolerant strategy would have allowed the second phase of invasion into harsher and poorer habitats. Such evolutionary adjustments could explain the time lag between the species' first introduction and the beginning of invasion (Richards et al. 2006).

It appeared that introduced tetraploid genotypes had an intermediate growth strategy as compared to strategies adopted by diploid and tetraploid geocytotypes within their native range (Fig. 3). With such an intermediate strategy, introduced tetraploid geocytotypes could have a higher potential to deal with various or changing environments since they could be able to shift their growth strategy between conservative defence-oriented and exploitative-competitive characteristics. For $C$. stoebe, this is confirmed by the niche shift observed in tetraploid genotypes in the introduced range and the broader environmental conditions tolerated by these genotypes (Broennimann et al. 2007; Treier et al. 2009).

Acknowledgments This project was funded by the National Centre of Competence in Research (NCCR) Plant Survival, research programme of the Swiss National Science Foundation. We thank Joanne Félix, Elena Rossel and Damien Pasche for technical assistance. We are grateful to Olivier Broennimann, Signe Normand and Urs Treier for collecting seeds of Centaurea stoebe, and to Daniel Prati and Isabelle Olivieri for providing seeds of Senecio inaequidens. We also thank the University of Lausanne for providing greenhouse facilities and material. This paper benefited from discussions and comments by Sandra Lavorel, Séverine Vuilleumier and Pierre Liancourt. The authors are grateful to two anonymous reviewers whose comments greatly improved the manuscript. This experiment complied with the Swiss regulation for invasive plant experimentations, as stated by the Federal Office for the Environment (FOEN).

\section{References}

Bornkamm R (2002) On the phytosociological affiliations of an invasive species Senecio inaequidens in Berlin. Preslia Praha 74:395-407

Bossdorf O, Lipowsky A, Prati D (2008) Selection of preadapted populations allowed Senecio inaequidens to invade Central Europe. Divers Distrib 14:676-685

Broennimann O, Treier UA, Muller-Scharer H, Thuiller W, Peterson AT, Guisan A (2007) Evidence of climatic niche shift during biological invasion. Ecol Lett 10:701-709

Campobasso G, Sobhian R, Knutson L, Pastorino AC, Dunn PH (1994) Biology of Pterolonche inspersa (Lep, Pterolonchidae), a biological control agent for Centaurea diffusa and Centaurea maculosa in the United States. Entomophaga 39:377-384

Chun YJ, Collyer ML, Moloney KA, Nason JD (2007) Phenotypic plasticity of native vs. invasive purple loosestrife: a two-state multivariate approach. Ecology 88:1499-1512

Colautti RI, Grigorovich IA, MacIsaac HJ (2006) Propagule pressure: a null model for biological invasions. Biol Invasions 8:1023-1037

Coomes DA, Grubb PJ (2003) Colonization, tolerance, competition and seed-size variation within functional groups. Trends Ecol Evol 18:283-291

Cornelissen JHC, Lavorel S, Garnier E, Diaz S, Buchmann N, Gurvich DE, Reich PB, ter Steege H, Morgan HD, van der Heijden MGA, Pausas JG, Poorter H (2003) A handbook of protocols for standardised and easy measurement of plant functional traits worldwide. Aust J Bot 51:335-380

Daehler CC (2003) Performance comparisons of co-occurring native and alien invasive plants: implications for conservation and restoration. Annu Rev Ecol Evol Syst 34:183-211

Diaz S, Hodgson JG, Thompson K, Cabido M, Cornelissen JHC, Jalili A, Montserrat-Marti G, Grime JP, Zarrinkamar F, Asri Y, Band SR, Basconcelo S, Castro-Diez P, Funes G, Hamzehee B, Khoshnevi M, Perez-Harguindeguy N, Perez-Rontome MC, Shirvany FA, Vendramini F, Yazdani S, Abbas-Azimi R, Bogaard A, Boustani S, Charles M, Dehghan M, de Torres-Espuny L, Falczuk V, Guerrero-Campo J, Hynd A, Jones G, Kowsary E, KazemiSaeed F, Maestro-Martinez M, Romo-Diez A, Shaw S, 
Siavash B, Villar-Salvador P, Zak MR (2004) The plant traits that drive ecosystems: evidence from three continents. J Veg Sci 15:295-304

Dietz H, Edwards PJ (2006) Recognition that causal processes change during plant invasion helps explain conflicts in evidence. Ecology 87:1359-1367

Duncan C (2001) Knapweed management: another decade of changes. In: Smith L (ed) Proceedings of the First International Knapweed Symposium of the 21st Century. United States Department of Agriculture, Agricultural Research Service, Albany, CA, USA. Coeur d'Alene, Idaho, pp 1-7

Ellstrand NC, Schierenbeck KA (2000) Hybridization as a stimulus for the evolution of invasiveness in plants? Colloquium on Variation and Evolution in Plants and Micro-organisms - toward a new synthesis 50 years after Stebbins. National Academy of Science, Irvine, pp 7043-7050

Ernst WHO (1998) Invasion, dispersal and ecology of the South African neophyte Senecio inaequidens in The Netherlands: from wool alien to railway and road alien. Acta Botanica Neerlandica 47:131-151

Facon B, Genton BJ, Shykoff J, Jarne P, Estoup A, David P (2006) A general eco-evolutionary framework for understanding bioinvasions. Trends Ecol Evol 21:130-135

Goldberg DE, Landa K (1991) Competitive effect and response: hierarchies and correlated traits in the early stages of competition. J Ecol 79:1013-1030

Grime JP (1977) Evidence for existence of 3 primary strategies in plants and its relevance to ecological and evolutionary theory. Am Nat 111:1169-1194

Grime JP (1979) Plant strategies and vegetation processes. Wiley, Chichester

Guesewell S, Jakobs G, Weber E (2006) Native and introduced populations of Solidago gigantea differ in shoot production but not in leaf traits or litter decomposition. Funct Ecol 20:575-584

Henery ML, Bowman G, Mráz P, Treier UA, Gex-Fabry E, Schaffner U, Müller-Schärer H (2010) Evidence for a combination of pre-adapted traits and rapid adaptive change in the invasive plant Centaurea stoebe. J Ecol 98:800-813

Hierro JL, Maron JL, Callaway RM (2005) A biogeographical approach to plant invasions: the importance of studying exotics in their introduced and native range. $J$ Ecol 93:5-15

Hook PB, Olson BE, Wraith JM (2004) Effects of the invasive forb Centaurea maculosa on grassland carbon and nitrogen pools in Montana, USA. Ecosystems 7:686-694

Hufbauer RA, Torchin ME (2007) Integrating ecological and evolutionary theory of biological invasions. In: Nentwig W (ed) Biological invasions. Springer, Berlin, Heidelberg, pp 79-96

Keddy P, Fraser LH, Wisheu IC (1998) A comparative approach to examine competitive response of 48 wetland plant species. J Veget Sci 9:777-786

Kolar CS, Lodge DM (2001) Progress in invasion biology: predicting invaders. Trends Ecol Evol 16:199-204

Kuster EC, Kuhn I, Bruelheide H, Klotz S (2008) Trait interactions help explain plant invasion success in the German flora. J Ecol 96:860-868
Lafuma L, Balkwill K, Imbert E, Verlaque R, Maurice S (2003) Ploidy level and origin of the European invasive weed Senecio inaequidens (Asteraceae). Plant Syst Evol 243:59-72

Lee CE (2002) Evolutionary genetics of invasive species. Trends Ecol Evol 17:386-391

Lockwood JL, Cassey P, Blackburn T (2005) The role of propagule pressure in explaining species invasions. Trends Ecol Evol 20:223-228

Muth NZ, Pigliucci M (2006) Traits of invasives reconsidered: Phenotypic comparisons of introduced invasive and introduced noninvasive plant species within two closely related clades. Am J Bot 93:188-196

Navas ML, Moreau-Richard J (2005) Can traits predict the competitive response of herbaceous Mediterranean species? Acta Oecol 27:107-114

Petit C, Thompson JD (1999) Species diversity and ecological range in relation to ploidy level in the flora of the Pyrenees. Evol Ecol 13:45-66

Pimentel D, Lach L, Zuniga R, Morrison D (2000) Environmental and economic costs of nonindigenous species in the United States. Bioscience 50:53-65

Pinheiro JC, Bates DM (2000) Mixed-effects model in S and S-plus. Springer, New York

Poorter H, De Jong R (1999) A comparison of specific leaf area, chemical composition and leaf construction costs of field plants from 15 habitats differing in productivity. New Phytol 143:163-176

Prentis PJ, Wilson JRU, Dormontt EE, Richardson DM, Lowe AJ (2008) Adaptive evolution in invasive species. Trends Plant Sci 13:288-294

Prieur-Richard AH, Lavorel S, Grigulis K, Dos Santos A (2000) Plant community diversity and invisibility by exotics: invasion of Mediterranean old fields by Conyza bonariensis and Conyza canadensis. Ecol Lett 3:412-422

Pyšek P, Richardson DM (2007) Traits associated with invasiveness in alien plants: where do we stand? In: Nentwig W (ed) Biological invasions. Springer, Berlin

Reich PB, Walters MB, Ellsworth DS (1992) Leaf life-span in relation to leaf, plant, and stand characteristics among diverse ecosystems. Ecol Monogr 62:365-392

Reich PB, Ellsworth DS, Walters MB, Vose JM, Gresham C, Volin JC, Bowman WD (1999) Generality of leaf trait relationships: A test across six biomes. Ecology 80:1955-1969

Richards CL, Bossdorf O, Muth NZ, Gurevitch J, Pigliucci M (2006) Jack of all trades, master of some? On the role of phenotypic plasticity in plant invasions. Ecol Lett 9:981-993

Richardson DM, Pysek P (2006) Plant invasions: merging the concepts of species invasiveness and community invasibility. Prog Phys Geogr 30:409-431

Silvertown J (2004) Plant coexistence and the niche. Trends Ecol Evol 19:605-611

Skinner K, Smith L, Rice P (2000) Using noxious weed lists to prioritize targets for developing weed management strategies. Weed Sci 48:640-644

Soltis PS, Soltis DE (2000) The role of genetic and genomic attributes in the success of polyploids. Proc Natl Acad Sci USA 97:7051-7057 
Suding KN, Goldberg DE, Hartman KM (2003) Relationships among species traits: separating levels of response and identifying linkages to abundance. Ecology 84:1-16

Treier UA, Broennimann O, Normand S, Guisan A, Schaffner U, Steinger T, Müller-Schärer H (2009) Shift in cytotype frequency and niche space in the invasive plant Centaurea maculosa. Ecology 90:1366-1377

Turnbull LA, Coomes D, Hector A, Rees M (2004) Seed mass and the competition/colonization trade-off: competitive interactions and spatial patterns in a guild of annual plants. J Ecol 92:97-109

Venables WN, Ripley BD (1999) Modern applied statistics with S-Plus. Springer-Verlag, New-York

Von Holle B (2005) Biotic resistance to invader establishment of a southern Appalachian plant community is determined by environmental conditions. J Ecol 93:16-26

Watson AK, Renney AJ (1974) The biology of Canadian weeds: Centaurea diffusa and Centaurea maculosa. Can J Plant Sci 54:687-701

Weber E, Schmid B (1998) Latitudinal population differentiation in two species of Solidago (Asteraceae) introduced into Europe. Am J Bot 85:1110-1121
Weiher E, van der Werf A, Thompson K, Roderick M, Garnier E, Eriksson O (1999) Challenging theophrastus: a common core list of plant traits for functional ecology. J Veget Science 10:609-620

Westoby M (1998) A leaf-height-seed (LHS) plant ecology strategy scheme. Plant Soil 199:213-227

Whitney KD, Gabler CA (2008) Rapid evolution in introduced species, 'invasive traits' and recipient communities: challenges for predicting invasive potential. Divers Distrib 14:569-580

Williamson M (1996) Biological invasions. Chapman and Hall, London

Wright IJ, Reich PB, Westoby M, Ackerly DD, Baruch Z, Bongers F, Cavender-Bares J, Chapin T, Cornelissen JHC, Diemer M, Flexas J, Garnier E, Groom PK, Gulias J, Hikosaka K, Lamont BB, Lee T, Lee W, Lusk C, Midgley JJ, Navas ML, Niinemets U, Oleksyn J, Osada N, Poorter H, Poot P, Prior L, Pyankov VI, Roumet C, Thomas SC, Tjoelker MG, Veneklaas EJ, Villar R (2004) The worldwide leaf economics spectrum. Nature 428:821-827 